\title{
A study of Ultrasonic guided wave NDT Technique based on PEEK rod
}

\author{
Yang $\mathrm{Hu}^{1^{*}}$, Ma Wenliang ${ }^{2}$ and Wang Zhaoba ${ }^{1}$ \\ ${ }^{1}$ National Key Laboratory For Electronic Measurement Technology, North \\ University of China, Taiyuan 030051, China \\ ${ }^{2}$ Inner Mongolia First Machinery Group Corporation, Baotou 014030, China) \\ yanghu@nuc.edu.cn
}

\begin{abstract}
The ultrasonic buffer rod used for polymer testing under the high temperature, not only needs high transmission ultrasound characteristic of SNR, but also low acoustic attenuation, high temperature and strong mechanical properties etc are needed. The role PEEK rod plays in this paper is transmitting ultrasonic guided waves and temperature buffer, so the design of PEEK rod is the key. Through the experimental analysis, the SNR with different diameter and length is gave, and the effect on the ultrasonic characteristics of echo signal is also presented, in order to ensure the high SNR. The conclusions provide a theoretical basis for NDT.
\end{abstract}

Keywords: PEEK rod; Ultrasonic guided wave; Signal Noise Ratio (SNR); Non Destructive Testing (NDT)

\section{Introduction}

The ultrasonic buffer rod which used for polymer testing under the high temperature, not only needs high transmission ultrasound characteristic of SNR, but also low acoustic attenuation, high temperature and strong mechanical properties etc are needed, but normal non-metallic materials (such as HDPE) do not satisfy these conditions. Metal buffer rod is mostly used in ultrasonic testing of high temperature, Because of higher melting point and mechanical strength. However, its higher acoustic velocity leads to intensive trailing signal, which would effect the extraction of feature signal. As the development of plastic processing technology, new composite materials with high melting point and high strength are playing an important role in the industrial field. However, whether these materials are satisfied to ultrasonic buffer rod is also need a further examine in its ultrasonic properties [1-4].

PEEK has high heat resistance (the heat deformation temperature is $300^{\circ} \mathrm{C}$ after the fiber reinforced), hot-water resistance (can be used in the $200-260^{\circ} \mathrm{C}$ steam), creep and fatigue resistance (the highest in thermoplastics), corrosion resistance (no solvent can corrode it accept concentrated sulfuric acid and concentrated nitric acid ), radiationresistant and flame resistance, mechanical strength and good electrical insulation characteristics etc, which can be used for a long time at $260^{\circ} \mathrm{C}$ and $80 \mathrm{MPa}$ [5-6].

\section{The Effect on Buffer Rod Material to the Propagation of Ultrasonic Guided Wave}

Ultrasonic performance is tested for high-density polyethylene (HDPE) and polyether-ether-ketone (PEEK) of two kinds of engineering plastics, and the

\footnotetext{
* Corresponding author. Tel: +8618435131188

E-mail: yanghu@nuc.edu.cn
} 
compare with the typical metallic materials (steel and aluminum) is made. The material properties and the size of four cylindrical buffer rods are listed in Table 1. HDPE with characteristics of high crystallinity, tensile strength, high distortion temperature, viscosity and chemical stability, is commonly used as engineering plastic. PEEK is a kind of special engineering plastics, with good resistance to chemicals, radiation and flame, excellent electrical properties, good toughness, and good wear resistance at high temperatures [7-8].

$2.5 \mathrm{MHz}$ narrow pulse probe with $14 \mathrm{~mm}$ outer diameter and the $10 \mathrm{~mm}$ wafer diameter is used for the test. The probe is put at the center of one end of the buffer rod, ultrasonic guided wave propagate to another end and then reflected back, finally received by the probe. The sampling frequency of ultrasound acquisition card is $50 \mathrm{MHz}, 8$-bit quantization and in the range of $-1 \mathrm{~V} \sim 1 \mathrm{~V}$. Acquisition of guided wave echo signal as shown in Figure 1. Due to the different damping of different material, the attenuation of guided wave echo signal is also different which is in sequence of $80 \mathrm{~dB}, 80 \mathrm{~dB}, 28 \mathrm{~dB}$ and $55 \mathrm{~dB}$.

Table 1. Test Cylindrical Buffer Rod Material Properties and Dimensions

\begin{tabular}{|c|c|c|c|c|c|c|c|}
\hline Material & $\begin{array}{c}\text { Diameter } \\
(\mathrm{mm})\end{array}$ & $\begin{array}{c}\text { Length } \\
(\mathrm{mm})\end{array}$ & $\begin{array}{c}\text { Longitudinal } \\
\text { wave velocity } \\
(\mathrm{m} / \mathrm{s})\end{array}$ & $\begin{array}{c}\text { Shear wave } \\
\text { velocity } \\
(\mathrm{m} / \mathrm{s})\end{array}$ & $\begin{array}{c}\text { Density } \\
\left(\mathrm{kg} / \mathrm{m}^{3}\right)\end{array}$ & $\begin{array}{c}\text { P-wave } \\
\text { impedance } \\
\left(10^{6} \mathrm{~kg} / \mathrm{m}^{2} \mathrm{~s}\right)\end{array}$ & $\begin{array}{c}\text { Shear wave } \\
\text { impedance } \\
\left(10^{6} \mathrm{~kg} / \mathrm{m}^{2} \mathrm{~s}\right)\end{array}$ \\
\hline Aluminum & 20 & 100 & 6300 & 3100 & 2700 & 17.0 & 8.37 \\
\hline Steel & 20 & 100 & 5880 & 3200 & 8030 & 47.2 & 25.7 \\
\hline HDPE & 20 & 70 & 2290 & 920 & 950 & 2.18 & 0.87 \\
\hline PEEK & 11.8 & 70 & 2550 & 1150 & 1290 & 3.29 & 1.48 \\
\hline
\end{tabular}

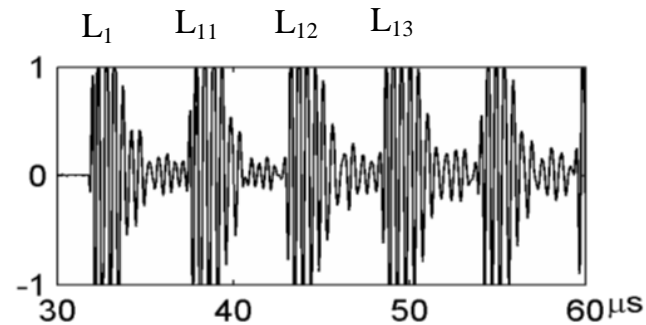

(a) Aluminum rod (80dB)

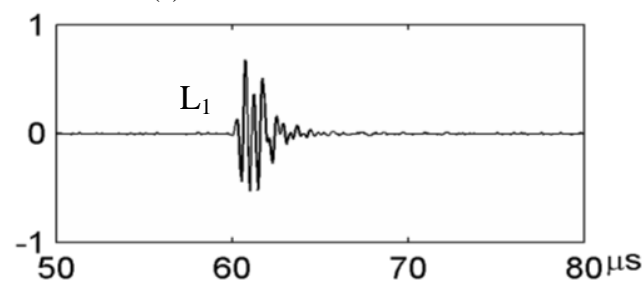

(c) HDPE rod $(28 \mathrm{~dB})$

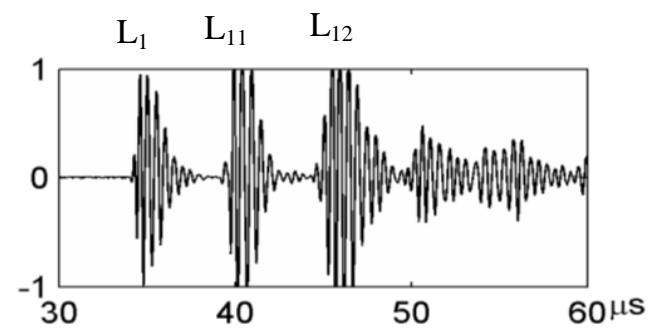

(b) Steel rod $(80 \mathrm{~dB})$

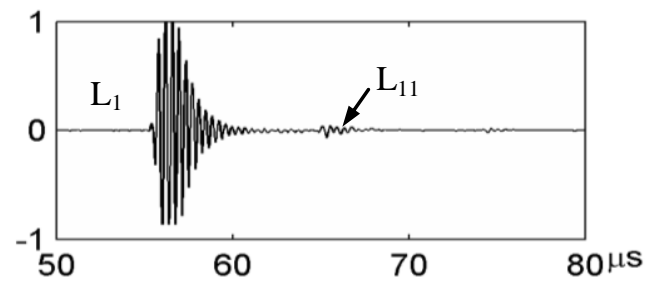

(d) PEEK rod $(55 \mathrm{~dB})$

\section{Figure 1. Ultrasonic Echo Wave Through a Cylindrical Buffer Rod End}

From Figure 1 it may be seen that the trailing signal of non-metal buffer rod is much smaller than that of metal buffer rod. The main reason has two aspects, on the one hand, the attenuation of non-metallic is relatively larger

and then decreases the energy of trailing echo; on the other hand, the acoustic velocity of non-metal is small, so the interval of trailing echo signal is relatively wide in the case of the same diameter.

In practical testing, the SNR of ultrasonic echo should be the ratio of characteristics signal echo and trailing pulse, rather than the ratio of buffer rod's main pulse and trailing 
pulse. It is certainly that if the ratio of main pulse and trailing pulses decreases, then the ratio of characteristics signal echo and trailing pulse would decrease [5].

The characteristics signal echo is not only related to buffer rod, but also the attenuation of polymer and the interface transmittance between buffer rod and polymer. So the interface transmittance should be considered when the high SNR of the buffer rod is designed. Transmittance depends on the acoustic impedance of two media, the higher acoustic impedance of the polymer and lower of the buffer rod, the higher energy of the characteristics signal echo. The acoustic impedance of non-metal is lower than the metal and matches with polymer, so it has a higher transmittance, the transmittance of four rods in Table 1 is shown in Table 2.

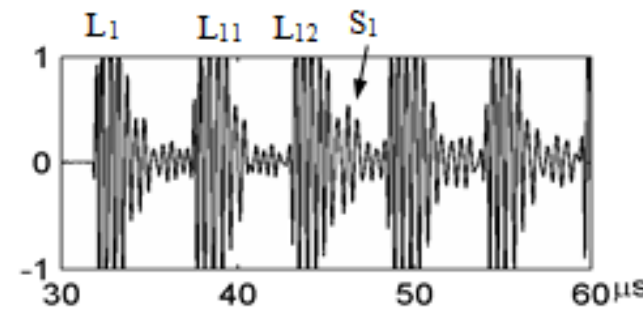

(a) Aluminum rod ( $80 \mathrm{~dB})$

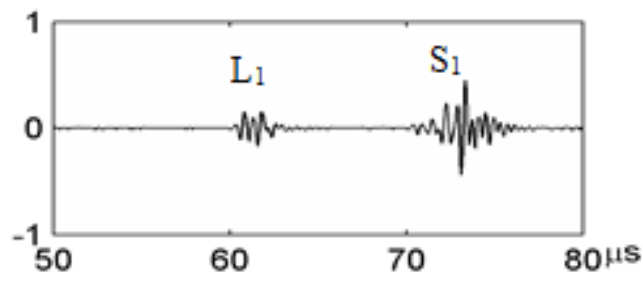

(c) HDPE rod (28dB)

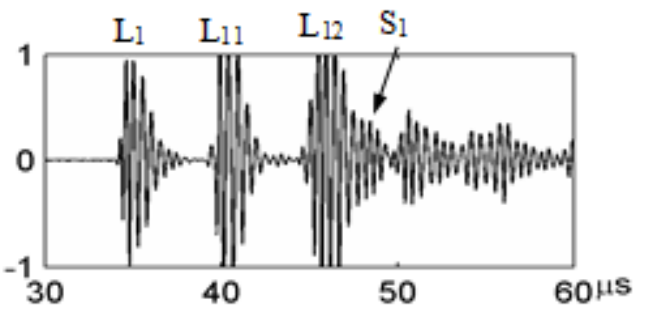

(b) Steel rod ( $80 \mathrm{~dB})$

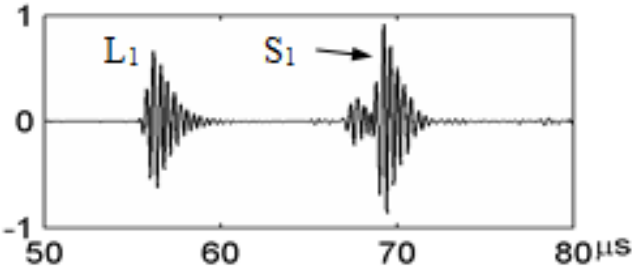

(d) PEEK rod (55dB)

\section{Figure 2 The Echo Reflected by Ultrasonic Guided Wave Through Cylindrical Buffer Rod}

As shown in Figure 2, when using the metal buffer rod, the detection signal is small and substantially submerged in the trailing signal. But when choosing the non-metal buffer rod, the detection signal is more obvious, and shows little effect on characteristics signal. If the ratio of characteristic signal and trailing signals is defined as characteristic signal noise ratio (CSNR), then the CSNR of Figure 2 (a), (b) are under -10dB and Figure 2 (c), (d) are $30 \mathrm{~dB}$ above. The main reason is that metal material has higher acoustic impedance compared to non-metal materials, when using non-metal buffer rods, ultrasonic has higher transmittance in the interface of buffer rod and detection material. Comparing Figure 1 with Figure 2 can be found that the main pulses change a little in (a) and (b), but significantly reduced in (c) and (d).

To sum up, the non-metal buffer rod has the characteristics of low acoustic impedance and acoustic velocity, and has more advantages than the metal when used for the detection of polymer.

\section{The SNR of PEEK Buffer Rod with Different Diameter and Length}

In the practical application, there still exist some uncertain factors that effect the time position of ultrasonic echo (such as, the influence of temperature to polymer velocity, the probable overlap of trailing echo and characteristic echo), so it is necessary to suppress the trailing pulse of buffer rod. Following is the analysis for SNR of PEEK buffer rod with different diameter and length [9-11].

As shown in Figure 3, the diameter of buffer rod is $10 \sim 16 \mathrm{~mm}$ and the length is $40 \sim 20 \mathrm{~mm}$. From the overall, the increase of diameter and the decrease of length will lead 
to the increase of SNR. Therefore, the larger diameter and shorter length, the better simulation results from the perspective of SNR. Figure 4 is some typical simulation echo. However, the installation, cooling and other factors should be taken into consider in practice, the diameter of buffer rod is not too large and the length should not be too short which generally not exceed $16 \mathrm{~mm}$ in diameter, length not less than $70 \mathrm{~mm}$ and the specific needs should according to the site conditions. According to Figure 3, if the length of buffer rod is $70 \mathrm{~mm}$ and the diameter is greater than $12 \mathrm{~mm}$, the SNR is greater than $18 \mathrm{~dB}$. If the diameter of buffer rod is $16 \mathrm{~mm}$ and the length is less than $200 \mathrm{~mm}$, the SNR is greater than $17 \mathrm{~dB}$. On the whole, in the use of the general field, PEEK cylindrical rod has a higher SNR. In the practical application, we can select the diameter and length by Figure 2 to achieve the maximizing SNR in the condition of effective installation and use. In addition, in the effective length and radial size range, we can improve the SNR by machining tapered, coated and other structures.

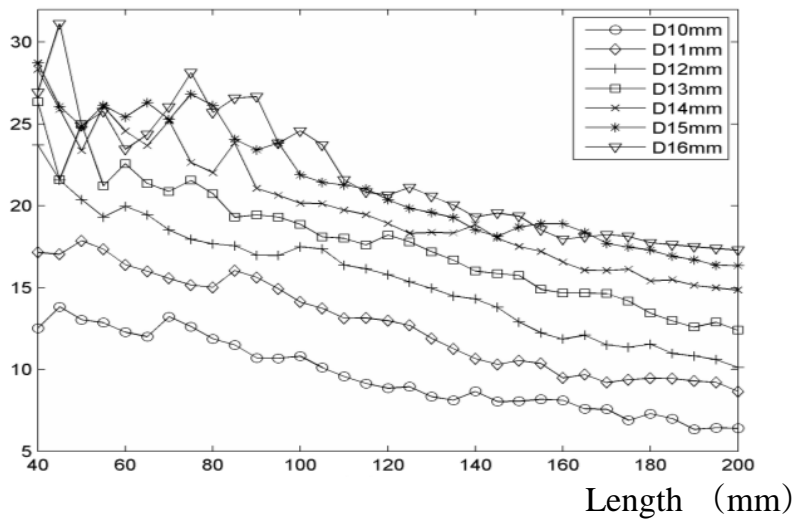

Figure 3. The SNR Analysis for Ultrasonic Echo of PEEK Cylindrical Rod

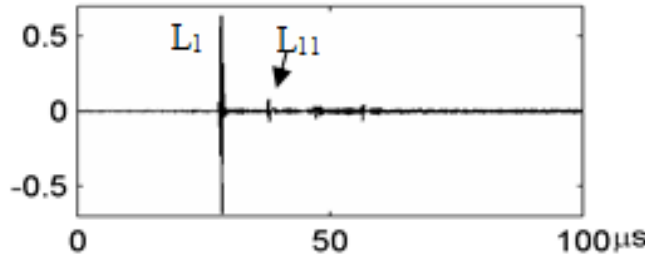

(a) length $70 \mathrm{~mm}$, diameter $12 \mathrm{~mm}$

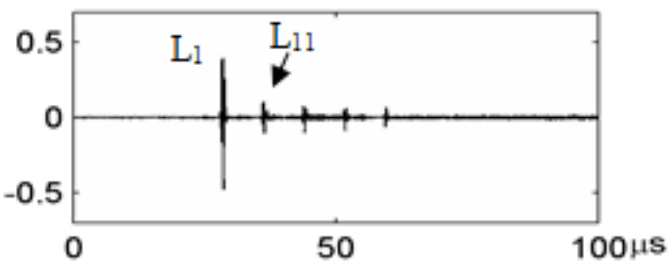

(c) length $70 \mathrm{~mm}$, diameter $10 \mathrm{~mm}$

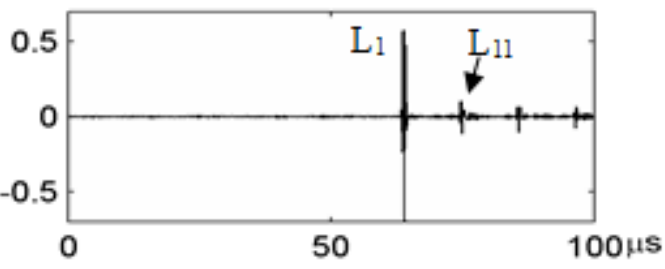

(b) length $160 \mathrm{~mm}$, diameter $14 \mathrm{~mm}$

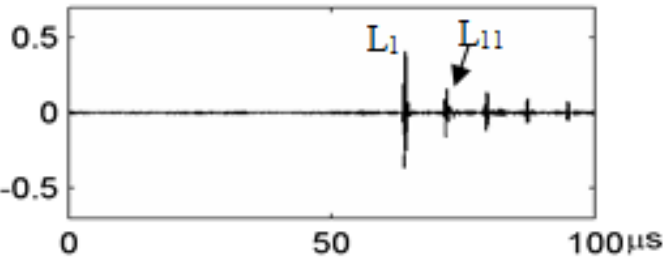

(d) length $160 \mathrm{~mm}$, diameter $10 \mathrm{~mm}$

\section{Figure 4. Typical Simulation Echo of PEEK Cylindrical Rod}

\section{The Design of Buffer Rod with Different Specifications}

Figure 5-7 shows the different length of buffer rod. Among the figures, what shown above is the whole figure and the following is the structure of buffer rod. The ultrasonic probe used is $2.5 \mathrm{MHz}$ narrow pulse probe, whose outer diameter is $14 \mathrm{~mm}$ and the chip diameter is $10 \mathrm{~mm}$. What shown in Figure 5 is cylindrical buffer rod and double cone buffer rod whose length is $160 \mathrm{~mm}$. The main part diameter of cylindrical buffer rod is $14 \mathrm{~mm}$, and the diameter which connected with the double tapered buffer rod and the probe is $14 \mathrm{~mm}$. What's more, the length of symmetric cone structural is $110 \mathrm{~mm}$, the 
minimum diameter is $12 \mathrm{~mm}$ and the maximum is $14 \mathrm{~mm}$, the inclined taper is $1^{\circ}$. The length of buffer rod in Figure 6 and Figure 7 are $111 \mathrm{~mm}$ and $101 \mathrm{~mm}$ respectively, and the diameter of main part is $14 \mathrm{~mm}$.



Figure 5. The Buffer Rod with Length of $160 \mathrm{~mm}$



Figure 6 The Buffer Rod with Length of $111 \mathrm{~mm}$

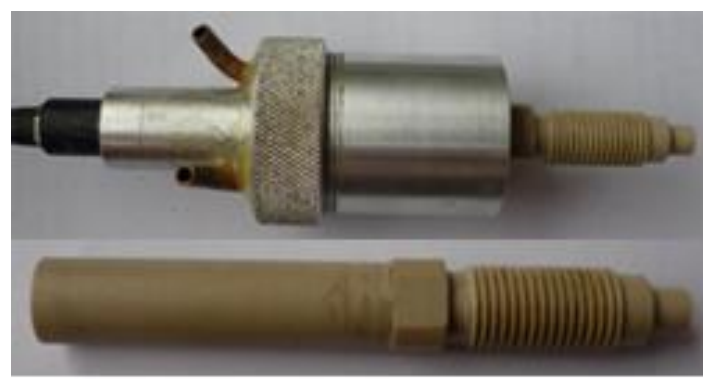

Figure 7. The Buffer Rod with length of $101 \mathrm{~mm}$

Figure 8 is the echo signal of ultrasonic detection for buffer rod under normal temperature. L in Figure (c) and (d) stands for the reflected echo which received in handling structure, Overall, trailing pulse L11 is smaller than main pulse L1, and the SNR is high. The trailing pulse L11 in Figure (b) is slightly less than that in Figure (a), which shows that conical buffer rod can inhibit trailing signal and improve SNR. In the actual production process of the buffer rod, if the length of the buffer rod is longer, then it can be considered by using tapered structure to improving SNR. But when the buffer rod is short and part of the length is used for installing and processing, what can be used for handling structure is very short, and it can not obviously improve the SNR.

And then, using the cylindrical rod also has a higher SNR (Figure 8 (c) and (d)). 


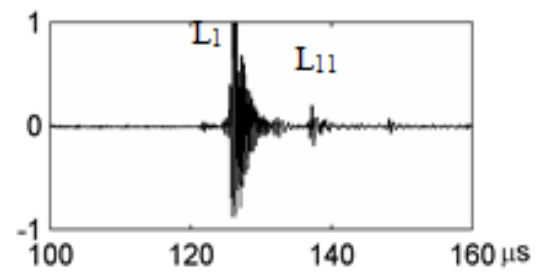

(a)Cylindrical buffer rod with length of $160 \mathrm{~mm}$

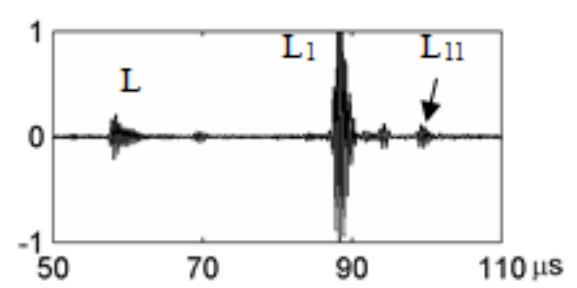

(c) Cylindrical buffer rod with length of $111 \mathrm{~mm}$

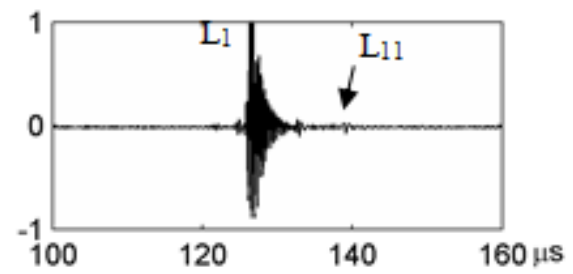

(b) Double cone buffer rod with length of $160 \mathrm{~mm}$

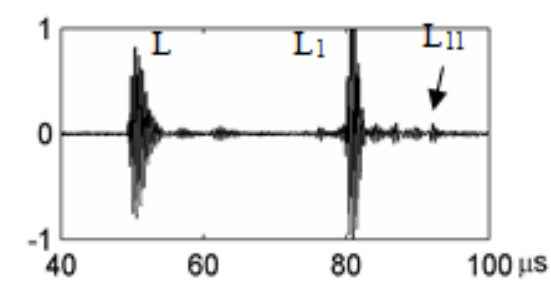

(d) Cylindrical buffer rod with length of $101 \mathrm{~mm}$

\section{Figure 8. The Echo Signal of Ultrasonic Detection for Buffer Rod with Different Specifications Under Normal Temperature}

\section{The Test of Temperature Properties for Buffer Rod}

In order to test the working of sensor in high temperature environment, a constant temperature cabinet shown in Figure 9 is used to control the working temperature, and the buffer rod is cylindrical structure.

Placing the fabricated LDPE block on a specific device, and the constant temperature cabinet is set to be $150^{\circ} \mathrm{C}$, then the characteristic echo signal of the LDPE whose thickness is $7.5 \mathrm{~mm}$ is tested under the condition of heated evenly. As shown in Figure 10, the detection characteristic signal is obvious, which prove that the sensor has the ability of detecting in the certain temperature, and the SNR is above $20 \mathrm{~dB}$.

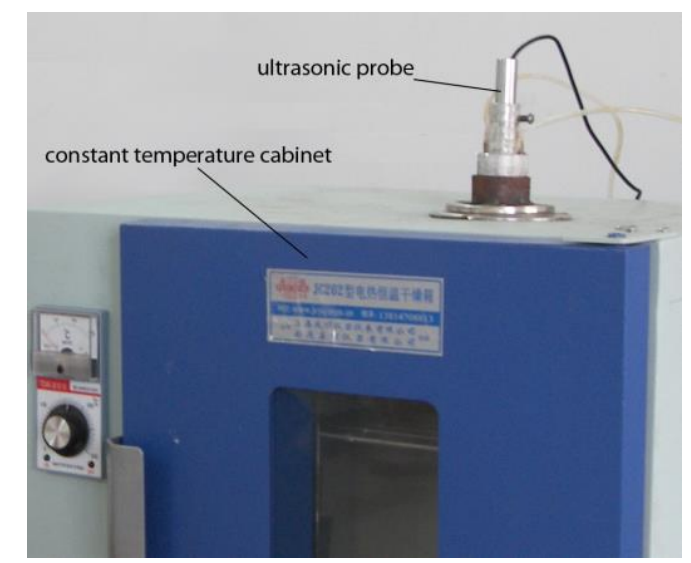

Figure 9. The Assembly Diagram of Ultrasonic Sensor in the Constant Temperature Cabinet 




(a)the total reflection echo of sensor end

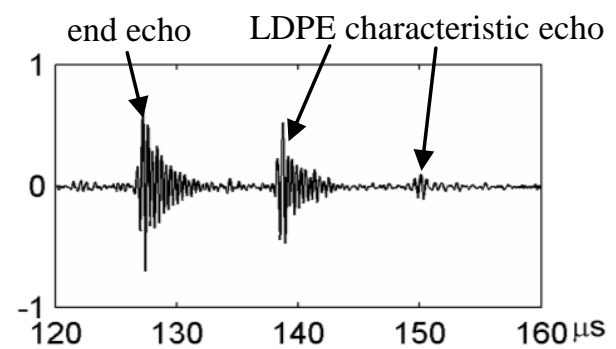

(b) the echo of LDPE with thickness of $7.5 \mathrm{~mm}$

Figure 10. The Echo Signal of Ultrasonic Sensor II under $150^{\circ} \mathrm{C}($ Cylindrical Buffer Rod with the Length of $160 \mathrm{~mm}$ )

Figure 10 shows the results that the ultrasonic sensor can be working under $150^{\circ} \mathrm{C}$ , so there is a need for further research of the sensor at the other temperatures. Set the ultrasonic sensor in the constant temperature cabinet as shown in Figure 9, the change of end-face reflection echo is tested through the change of temperature. It is found that the amplitude and time-based position of echo signal is changing with temperature in the course of the experiment, and Figure 11 lists the echo signal of some typical temperature.

Figure 11 shows the changes of detection echo signals with the changes of testing temperature. In a whole, with the increase of temperature, the time-based position of echo moved backward which indicating the decrease of average acoustic velocity of the buffer rod, and the amplitude of echo decreased which indicating that the average acoustical attenuation of the buffer rod increased. Although the changes of time-based position have an effect on the extraction of characteristic signal, it can be corrected by the corresponding signal processing techniques. But the changes of amplitude will affect the effective extraction and subsequent analysis of the characteristics signal. As shown in Figure 11 (f), the echo signal of surface reflection has been difficult to extract, and the characteristic signal of polymer would be much smaller than the actual monitoring. Figure 12 shows the changes of amplitude with temperature, which is obtained based on that of $20^{\circ} \mathrm{C}$.

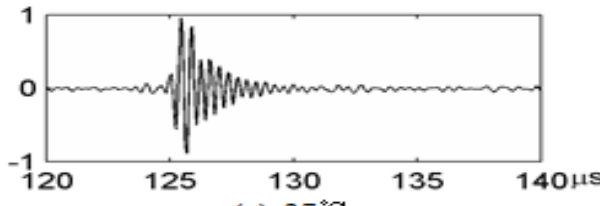

(a) $27^{\circ} \mathrm{C}$

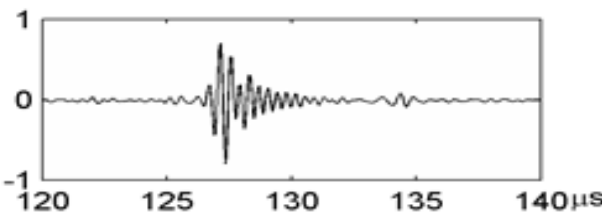

(c) $167.8^{\circ} \mathrm{C}$

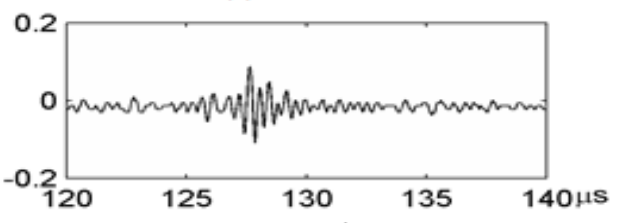

(e) $183.7^{\circ} \mathrm{C}$

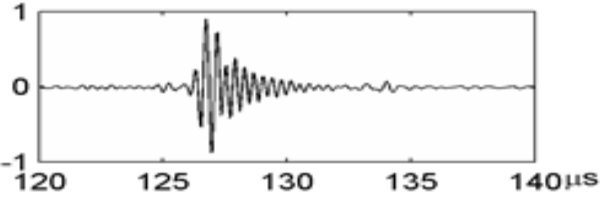

(b) $150^{\circ} \mathrm{C}$



(d) $171.8^{\circ} \mathrm{C}$

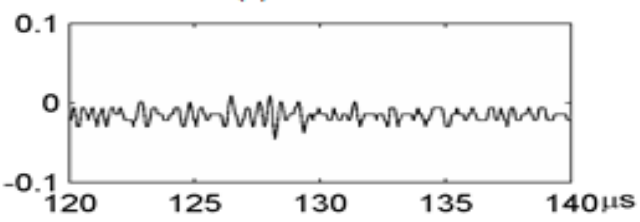

(f) $195.8^{\circ} \mathrm{C}$

Figure 11. The Changes of Echo Signals with Certain Testing Temperature 


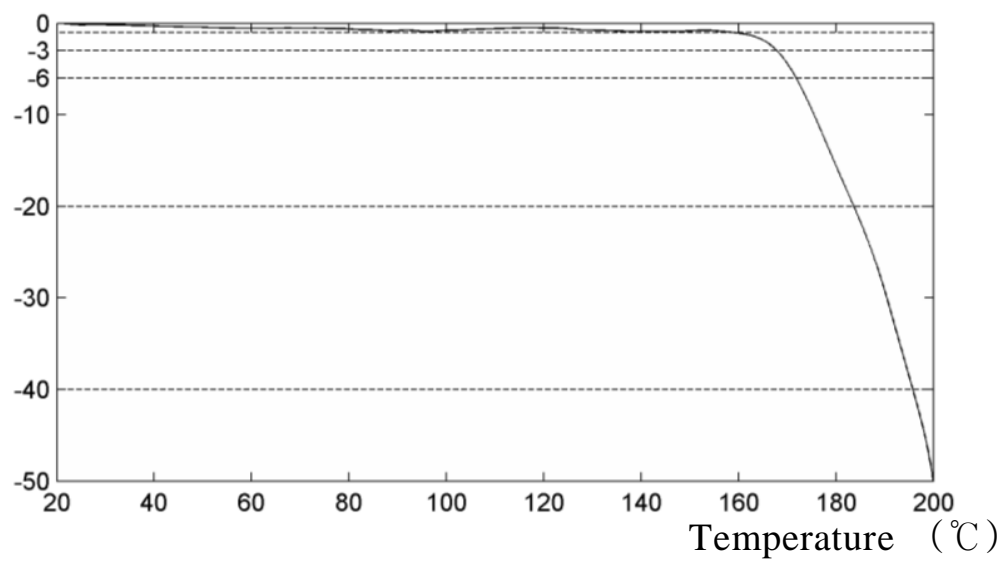

Figure 12. The Relationship between the Amplitude and Temperature

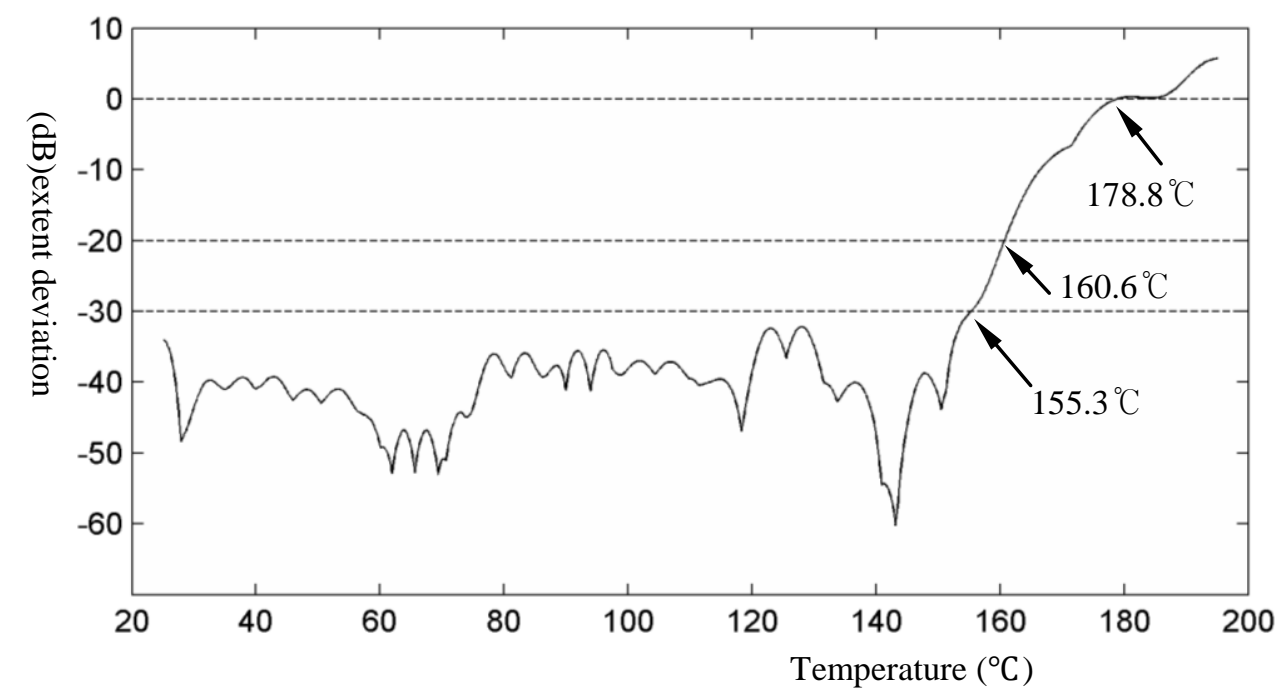

Figure 13. The Analysis of $\pm 5^{\circ} \mathrm{C}$ Temperature Deviation to Amplitude
Deviatio

As you can see from Figure 12 , when the temperature is between $20^{\circ} \mathrm{C}$ and $158.8^{\circ} \mathrm{C}$, the change of amplitude is in the range of $1 \mathrm{~dB}$. When the temperature higher than $158.8^{\circ} \mathrm{C}$, the amplitude decreased with the increasing of temperature. For example, when the temperature is $167.8^{\circ} \mathrm{C}$, the amplitude is the $3 \mathrm{~dB}$ of room temperature $\left(20^{\circ} \mathrm{C}\right)$; when the temperature is $171.8^{\circ} \mathrm{C}, 183.7^{\circ} \mathrm{C}$ and $195.8^{\circ} \mathrm{C}$, the attenuation is $6 \mathrm{~dB}, 20 \mathrm{~dB}$ and $40 \mathrm{~dB}$ respectively.

In the actual process of polymer extrusion, the deviation of temperature control will lead to the deviation of amplitude of characteristic signal. Figure13 indicates the changes of the maximum deviation of signal amplitude with the center temperature within the range of $\pm 5^{\circ} \mathrm{C}$.

As shown in Figure 13, when the temperature is lower than $155.3^{\circ} \mathrm{C}$, the deviation of amplitude is less than $30 \mathrm{~dB}$ (less than $3 \%$ ); when the temperature is lower than $160.6^{\circ} \mathrm{C}$, the deviation of amplitude is less than $30 \mathrm{~dB}(10 \%$ or less); and when the temperature is higher than $178.8^{\circ} \mathrm{C}$, the deviation of amplitude is greater than $0 \mathrm{~dB}$ (the maximum deviation is equal to itself). All the analysis shows that the temperature has little effect on the amplitude when the temperature lower than $155.3{ }^{\circ} \mathrm{C}$, and greater effect at the temperature of higher than $178.8^{\circ} \mathrm{C}$. If amplitude is considered as the characteristic 
quantity, there is a need to make sure that all tests are under a stable temperature and a further correction to ultrasonic echo.

Variation curves of Figure 12 and Figure 13 reflect the general trend of ultrasonic sensor with the change of temperature, but the critical temperature for different screw extruder is not exactly the same. Because the average attenuation of buffer rod in not entirely determined by the temperature of constant temperature cabinet (or the temperature of polymer and barrel), also with the length of buffer rod who is in a high temperature state. In the practical test, the length of buffer rod in contact with barrel is different for different screw extruder, therefore a difference is made to the finally amplitude. In the test, the length of sensor under high temperature is $30 \mathrm{~mm}$, and the actual wall thickness of barrel is less than $20 \mathrm{~mm}$. what's more, the temperature of polymer is higher than that of barrel, so the critical temperature would increase when the Figure 12 and Figure 13 are applied to the actual screw extruder.

In summary, four kinds of buffer rod the paper give can be normally worked under 160 ${ }^{\circ} \mathrm{C}$, and the temperature has little effect on the amplitude of signal. But when the temperature is higher than $180^{\circ} \mathrm{C}$, it has a greater effect. If taking the amplitude as the characteristic quantity, it must ensure that the experiment is conducted in the stable temperature, or else the echo signal must be corrected for temperature acquisition. For higher temperature environments, ultrasonic receiving card is required to have a large enough gain and shorter buffer rod, so as to ensure that the characteristics echo signal is large enough. But it is generally not suitable for on-line monitoring.

\section{Conclusions}

(1) Analyzing the effects of buffer rod material on ultrasonic echo signal, studying the effects of the sound attenuation, acoustic velocity and acoustic impedance of the buffer rod on the end echo signal, trailing signal and the detection characteristics echo signal. The results show that non-metal buffer rod has more advantages than the metal buffer rod.

(2) Taking the PEEK as buffer rod material, the relationship between the diameter, length and the SNR of ultrasonic echo is analyzed combined with the results of ultrasonic guided wave theory, which providing the basis for the design of the buffer rod dimensions.

(3) The buffer rod is designed for testing a variety of polymer and filler mixtures, providing the basis for NDT technology of the high temperature polymer.

\section{References}

[1] Ikuo ham., Dikky Burhan, Hiroshi Aso, ect.. Ultrasonic in-line sensors for inclusion detection in liquid metals, J. IEEE Ultraconics Symposium. 2002: 811-814.

[2] Ono Y. Jen C.K., Su C.Y.. Aluminum buffer rods for ultrasonic monitoring at elevated temperatures, J. IEEE Transactions on Ultrasonics, Ferroelectrics, and Frequency Control. 2005, 52(6):1042-1047.

[3] Jen C.K., Legoux J.G., Parent L.. Experimental evaluation of clad metallic buffer rods for high temperature ultrasonic measurements, J. NDT\&E International. 2000; 33(3): 145-153.

[4] Franca D.R., Jen C.K., Nguyen K.T., et al. Ultrasonic in-Line monitoring of polymer extrusion, J. Polymer Engineering and Science. 2000; 40(7): 82-94.

[5] Garcia A.J., Yan Y., Prego J.L., ect.. Noise level analysis in buffer rod geometries for ultrasonic sensors, J. Ultrasonics. 2006, 44:1093-1100.

[6] Benammar A., Drai R., Guessoum A.. Detection of delamination defects in CFRP materials using ultrasonic signal processing, J. Ultrasonics. 2008, 48: 731-738.

[7] Ultrasonic Monitoring Technology for Polymer Compounding Extrusion. Journal of Testing and Evaluation. 2010, 38(1):83-87.

[8] Analysis of Sound Ray Theory and FEM for Ultrasonic Propagation in a Finite Rod. Indian Journal of Pure \& Applied Physics. 2009, 47(8): 572-575.

[9] Villanueva M.P., Cabedo L. , Gimenez E., et al.. Study of the dispersion of nanoclays in a LDPE matrix using microscopy and in-process ultrasonic monitoring, J. Polymer Testing. 2009, 28: 277-287. 
[10] Illiger S.R., Fadnis C., Demappa T., et al. Miscibility studies of HPMC/PEG blends in water by viscosity, density, refractive index and ultrasonic velocity method, J. Carbohydrate Polymers. 2009, 75 :484-488.

[11] Kobayashi M., Jen C.K., Bussiere J.F, et al. High-temperature integrated and flexible ultrasonic transducers for nondestructive testing, J. NDT\&E International. 2009, 42: 157-161.

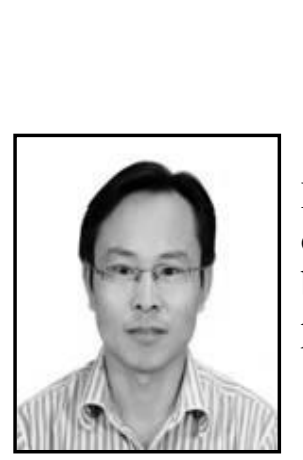

\section{Authors}

Yang Hu, male, was born in Jining, Inner Mongolia in Nov.1972. $\mathrm{He}$ is a Ph.D. and associate professor. He is now working in School of Instrument and Electronics, North University of China, has long been engaged in research and teaching work of computer information processing, nondestructive testing technology etc.

Ma Wenliang, male, was born in Damao Banner of Inner Mongolia in November 1971. He is a senior engineer in a group of Alec Rubber Products Co Ltd of Baotou city, Inner Mongolia, has long been engaged in research of polymer materials and rubber products.

Wang Zhaoba, male, was born in Yuncheng city, Shanxi province in July 1967. He is a Ph.D. and also a professor. He is qualified to hold the special allowance of the State Council. Now he works in School of Information and Communication Engineering of North University of China, has completed or taken part in a number of scientific research projects. His main research fields are: (1) information processing, reconstruction and fusion technology; (2) CT image processing technology; (3) detection technology and automation devices. 